\title{
SERVIÇOS DE SAÚDE PÚBLICA DO ESTADO DE SÃO PAULO
}

\author{
Comentários e sugestões * \\ RODOLFO DOS SANTOS MASCARENHAS ***
}

\section{CONCEITUAÇÃO}

Antes de entrar na questão básica dêste tema, é mister apresentarmos o conceito de Saúde e o de Saúde Pública. Para melhor esclarecimento desta última, daremos também a conceituação de níveis de Medicina Preventiva.

1.1 Saúde: A Constituição da Organização Mundial da Saúde (OMS), elaborada em 1946, é antecedida por uma declaração de princípios considerados fundamentais. O primeiro dêsses princípios está assim redigido:

"Saúde e um estado de completo bem-estar físico, mental e social e não apenas a ausência de doença ou enfermidade" ?.

Essa definição, ae efeito notável na evolução dos serviços de saúde pública dêstes últimos dois decênios em direção à integração das atividades de medicina curativa e de medicina preventiva, é, para nós, um tanto quanto idealista, afastando-se da realidade, pois não pode existir, neste mundo de contínuos desajustamentos onde "viver é lutar", um estado de "completo bem-estar", estado êste que nem sequer pode ser medido, a despeito do arsenal científico de hoje.

O bem-estar social diz respeito à sociedade e não ao indivíduo que sente os seus efeitos através dos reflexos que aquela produz em seu soma, em sua mente ou em ambos.

A expressão saúde-doença é indivisível, pois, entre saúde e doença não há limites nítidos, que possam ser demarcados com precisão. Não se pode dizer quando uma termina e se inicia a outra. Tanto isto é

Recebido para publicação em 11-11-1964.

* Trabalho da Cadeira de Técnica de Saúde Pública (Prof. Rodolfo dos Santos Mascarenhas) da Faculdade de Higiene e Saúde Pública da USP.

* Professor da Cadeira. 
Mascarenhas, R. dos S. Servicos de Saúde Pública no Estado de São Paulo... Arq. Fac. Hig. S. Paulo, 18:51-74, 1964.

verdade que a comissão elaboradora da Carta da OMS usou também o têrmo "enfermidade", para "aquêles casos em que o indivíduo com ou sem desordem apreciável na disposição material do corpo não possui esta ou aquela função ou a possui de maneira imperfeita ou irregular." ".

Para nós,

Saúde é um estado de bem-estar físico e mental e não a simples ausência de doença.

1.2 Níveis de prevenção: A Medicina Preventiva, partindo dos conceitos (1) do dinamismo do binômio saúde-doença e (2) da existência de aspectos preventivos no campo da Medicina Curativa e de aspectos curativos no campo da prevenção, fêz surgir o conceito de Medicina Integral, isto é, aquela que só pode ser vista como um todo indivisivel.

Leavell e Clark ${ }^{4}$, estudando os níveis de aplicação da Medicina Preventiva, dividiram-nos em cinco:

(1) Promoção da saúde, onde se estudam as medidas destinadas à melhoria da saúde;

(2) Prevenção da doença, em que são aplicadas as medidas específicas, inclusive as de Medicina Curativa, para impedir o aparecimento da moléstia;

(3) Diagnóstico e tratamento precoces, onde se estudam e aplicam medidas para que a doença seja precocemente identificada e tratada, impedindo-se, destarte, o seu agravamento;

(4) Limitação da incapacidade. Uma vez instalada a doença, medidas podem ser tomadas para minimizar, tanto quanto possivel, os seus efeitos negativos sôbre a capacidade física e mental do indivíduo;

(5) Reabilitação. Afastada a doença, esta pode ter deixado no indivíduo sequeelas somáticas ou psíquicas que diminuem sua capacidade. É preciso que indivíduos em tal estado sejam atendidos com medidas de readaptação, para favorecer a sua reintegração total ou parcial na sociedade.

1.3 Saúde Pública: Os objetivos da Saúde Pública são similares aos da Medicina - promoção, proteção e recuperação da saúde e reabilitação médico-social - porém, dirigidos para a sociedade, tendo como característica da ação a motivação da população ${ }^{6}$. 
Considerando que os níveis 3, 4 e 5 de Leavell e Clark - diagnóstico e tratamento precoces, limitação da incapacidade e reabilitação médico-social — podem ser designados por uma só expressão — recuperação da saúde -, apresentamos a seguinte definição:

Saúde Pública é a ciência que tem por objetivo a promoção, a proteção e a recuperação da saúde da comunidade, através de medidas de alcance coletivo e de motivação da população.

Uma das características da Saúde Pública é a sua aplicação integral a uma comunidade, sem a separação artificial entre medidas preventivas e medidas curativas. Outra característica é o seu aspecto multidisciplinar, requerendo para a sua execução uma equipe de técnicos - médico, enfermeiro, engenheiro, veterinário, dentista, estatístico, nutrólogo, cientista social, etc. - que recebe nas escolas de Saúde Pública um treinamento especial e uma filosofia capaz de uni-los em tôrno de um objetivo comum: saúde da comunidade.

\section{PADRÃO DE VIDA E SAÚdE PÚBLICA}

Já em 1920, o Professor Winslow ${ }^{12}$ afirmava em sua célebre definição que a ação da Saúde Pública se fazia através de "esforços organizados da comunidade", tendo, entre outros objetivos, o do "desenvolvimento da maquinaria social de modo a assegurar a cada indivíduo da comunidade um padrão de vida adequado para a manutenção de sua saúde".

Para êsse grande pensador norte-americano, há um padrão de vida mínimo abaixo do qual a saúde não subsiste e a maquinaria social necessita ser desenvolvida quando o padrão de vida não está adequado à manutenção da saúde dos cidadãos.

Êsses conceitos tiveram grande influência não só na conceituação da Saúde Pública, como também na formulação de diretrizes para vários de seus setores. É assim, exemplificando, que a implantação de um sistema de prioridades em uma comunidade de baixíssimo padrão de vida deve dar ênfase às medidas de ordem econômica que facilitarão o aumento do poder aquisitivo do povo, reservando-se à saúde pública recursos financeiros para atividades mínimas, isto é, para as relacionadas à vacinação contra doenças transmissíveis, à assistência médica e a certos aspectos do saneamento do meio físico.

Há uma correlação positiva entre doença e pobreza. Winslow ${ }^{13}$, em trabalho publicado pela OMS, discorrendo sôbre Economia e Saúde 
Pública, principalmente sôbre o círculo vicioso de pobreza e doença, afirma:

"O século XX enfrenta em escala global os mesmos problemas que Chadwick enfrentou em escala nacional um século atrás. Êste reconheceu que Londres não podia subsistir metade rica e metade pobre, metade sadia e metade doente."

Êsse pensamento sócio-econômico em relação a problemas de saúde pública refletiu, no preâmbulo da Constituição da Organização Mundial da Saúde, no conceito de saúde e, dentre outros, nos seguintes tópicos:

"O gôzo do melhor estado de saúde que lhe seja possivel atingir constitui um dos direitos fundamentais de todo ser humano, sejam quais fôrem sua raça, sua religião, suas opiniōes políticas, sua condição econômica ou social."

"Os Governos são responsáveis pela saúde de seus povos; êles poderão desincumbir-se dêsse encargo tomando as medidas sanitárias e sociais apropriadas." "

Horwitz ${ }^{3}$, tratando recentemente do mesmo assunto, com sua autoridade não apenas de ilustre professor de Medicina Preventiva, mas na qualidade de Diretor da Organização Pan-Americana da Saúde, afirma:

"O valor econômico da vida humana não é apenas uma questāo de poder aquisitivo, de consumo, de economias, mas também se mede, em grande parte, em têrmos de capacidade de produção. O dinheiro que a sociedade gasta com um ser humano, do seu nascimento até a maturidade, é considerável. Se um individuo deixa de produzir ou tem uma produçāo abaixo da sua quota, êsse investimento é perdido. Uma economia assim sobrecarregada significa uma sociedade estática, na qual a margem de lucro - quanto a uma vida melhor para o povo e uma existência mais progressista e segura é pequena e não permite aumento."

"A relação entre doença e pobreza - ou, em têrmos positivos, entre saúde e produção - é evidente. Uma produção baixa significa salários inadequados que, por sua vez, significam alimentação deficiente, falta de instrução conveniente, moradia sem condições de higiene, e assim por diante. Essas condições geram a doença e esta destrói a energia humana e faz baixar a produção, fechando uma espiral mortífera. Quando um país com recursos fixos gasta mais com a medicina curativa, gasta necessàriamente menos com a medicina preventiva e os programas de saúde pública. Em vista disso, tem de enfrentar uma incidência constantemente elevada da doença." 
MASCARENhas, R. dos $\mathbf{S}$. Servicos de Saúde Pública no Estado de Sāo Paulo... Arq. Fac. Hig. S. Paulo, 18:51-74, 1964.

Sauvy ${ }^{11}$, estudando a população dos países da América Latina, apresenta um gráfico, que reproduzimos e anexamos a êste trabalho, no qual se vê a correlação positiva entre renda "per capita" e esperança de vida ao nascer.

A Bolivia, que tem a renda "per capita" mais baixa da América Latina (72 dỏlares, 1959), apresenta uma vida média ao nascer que se situa entre 40-45 anos, ou seja, a mesma situação da Suécia na primeira metade do século passado. O Brasil tinha, no mesmo ano, uma renda "per capita" de 274 dólares e uma vida média de 50-58 anos, comparando-se com os Estados Unidos na segunda década dêste século. A Argentina, com uma renda "per capita" de 540 dólares, apresenta uma vida média de 63 a 66 anos, igual à dos Estados Unidos em 1945. Faz exceção a Venezuela, com a renda "per capita" mais elevada (1063 dólares) e com uma vida média de 53 e 57 anos. Esste fato talvez reflita má distribuição da riqueza, concentrada nas mãos de uma minoria.

Não nos cabe discutir em detalhes, nos limites estreitos dêste trabalho, a situação sócio-econômica do Estado de São Paulo. Faremos apenas alguns comentários.

Técnicos da Fundação Getúlio Vargas, estudando as características do subdesenvolvimento, assim se referem ao Brasil:

"Há, também, que considerar a própria divergência estrutural existente em cada pais. O Brasil, por exemplo, cada vez mais se caracteriza como país semidesenvolvido ao redor de São Paulo (Região Sul) e como extremamente subdesenvolvido na área econômica do Nordeste." :

O Estado de São Paulo apresenta-se em melhor situação de desenvolvimento econômico em relação aos demais estados do Brasil, com exceção da Guanabara, que é um estado-cidade.

A renda interna "per capita" do País era estimada, em 1960, em 26.789 cruzeiros, ou sejam, 143,3 dólares (segundo a cotação dêste no mercado mundial em 30 de junho daquele ano - $\mathrm{Cr} \$ 187,00)$. O estado de menor renda "per capita" era o do Piauí, com 7.710 cruzeiros (41,2 dólares); São Paulo apresentava, então, uma renda "per capita" de 47.601 cruzeiros (254,6 dólares) anuais.

No Brasil como um todo, da renda interna estimada de 1.901.176,8 milhões de cruzeiros, a agricultura - economia primária - contribuia com 536.065,1 milhões $(28,2 \%)$. Quanto ao Estado de São Paulo, num total de $617.604,9$ milhões de cruzeiros $(32,5 \%$ do total do País), a in- 
Mascarenhas, $R$. dos $\mathrm{S}$. Servicos de Saúde Pública no Estado de São Paulo... Arq. Fac. Hig. S. Paulo, 18:51-74, 1964.

dústria contribuiu com $204.941,5$ milhões $\left(33,2^{\prime}, c\right)$ e a agricultura com $144.866,4$ milhões $(23,5$ ćc $)$.

Se a capital de São Paulo e algumas regiōes limitrofes podem ser pode ser classificada ccmo elevada em relação ao nosso Pais, apresenta-se bem pequena em relação a paises tecnològicamente mais desenvolvidos. A renda interna "per capita", em dólares, em 1959, foi de 1.310 na Suécia e 2.089 nos Estados Unidos.

Em relação aos impostos, calculamos em outro trabalho "que cada brasileiro pagou, em 1960, 5.295 cruzeiros. A menor contribuição foi a do piauiense, com 431,6 cruzeiros; cada paulista pagou aos cofres públicos do País, em 1960, a importância de $14.206,7$ cruzeiros.

Se a capital de São Paulo e algumas regiōes limítrofes podem ser ccnsideradas áreas estaduais em desenvolvimento econômico, êsse desenvolvimento é bem menor em quase todo o planalto. Todo o litoral e algumas áreas menores como as adjacentes a Itapetininga, estão ainda em subdesenvolvimento. Essa situação reflete-se sôbre a saúde da coletividade, como veremos na parte que se segue.

\section{NIVEIS DE SAÚdE DO ESTADO DE SÃO PAULO}

Paradoxalmente, os niveis de saúde de uma comunidade são quase que exclusivamente levantados através de aspectos negativos, isto é, pela verificação da prevalência de doenças ou pela ocorrência de óbitos.

Um grupo de trabalho da OMS, referindo-se às dificuldades para se avaliar a saúde individual, declara o seguinte:

"As discussōes sôbre saúde e as tentativas para medi-la terminam quase inevitàvelmente numa referência aos dados de mortalidade. É certo que, no sentido estrito, a mortalidade não constitui uma indicaçāo de saúde, porém a experiência tem demonstrado que, via de regra, existe uma correspondência quantitativa entre êsses dois têrmos, de sorte que determinados valores de um permitem deduzir certos valores de outro." "s

Uma característica dos paises subdesenvolvidos è a deficiência de dados estatísticos. Muito pouco progredimos no que tange ao registro de óbitos, a partir de 1900, pois ainda é elevado o percentual daqueles cuja declaração é assinada por leigos ou que, mesmo assinada por médico, apresenta causa inclassificável. Os óbitos com causa mal ou não definida representavam em 1900 , na Capital, $19,7 \%$ do total, no Interior 
29,3\% e, no Estado, 27,4\%. Em sessenta e um anos, pouco melhoramos nesse aspecto, a não ser na Capital do Estado. Em 1961, êsses percentuais eram respectivamente de $2,0 \%$ na Capital, $23,0 \%$ no Interior e $17,3 \%$ no Estado. É por êsse motivo que não podemos nos utilizarmos, com precisão, de indicadores específicos baseados em óbitos por uma ou por um grupo de doenças.

Apresentaremos, em seguida, os indicadores de niveis de saúde para - Estado de São Paulo, segundo dados colhidos no Anuário do Departamento de Estatística do Estado de São Paulo ${ }^{14}$ e no Anuário Estatistico do Brasil ${ }^{15}$ e 16. Para referências internacionais, consultamos o Demographic Yearbook, da $\mathrm{ONU}^{1 i}$.

3.1 Coeficiente de mortalidade geral: O coeficiente de mortalidade geral é representado pelo número de óbitos anuais em mil habitantes de uma determinada área. Êsse indicador foi de 18,2 na Capital, 18,0 no Interior e 18,0 no Estado, no ano de 1900. Em 1960, a situação era a seguinte: 8,3 na Capital, 9,1 no Interior e 8,9 no Estado. Êsses dados revelam a grande melhoria na saúde coletiva do Estado a partir de 1900.

Para um cotejo internacional, apresentamos o mesmo coeficiente na Suécia, no ano de 1960: 9,8. Será que êsses dados revelariam uma situação melhor dos niveis de saúde de nosso Estado, em comparação com os de um país tecnològicamente tão desenvolvido como êsse da região nórdica? Ramos ${ }^{10}$, analisando a questão, afirma:

"Êsse indicador, entretanto, está sujeito a muitas restrições, que obrigam a certas cautelas no seu uso, principalmente em comparações internacionais."

Dos vários fatôres que restringem o uso dêsse indicador, invalidando-o para cotejo internacional, temos a estrutura da população quanto à idade e ao sexo. Esse mesmo autor demonstrou tal fato, calculando êsse coeficiente com a utilização de populações padronizadas por método direto e indireto. Estudando os coeficientes padronizados (1959), de mortalidade geral para as capitais dos estados brasileiros, verificou que o mais baixo era o do Município de São Paulo - 8,2 - e o mais elevado o de Maceió - 23,9.

3.2 Razão de mortalidade proporcional: Corresponde ao percentual de óbitos de pessoas com 50 e mais anos de idade sôbre o total de óbitos. Em 1900, apenas $13,2 \%$ dos óbitos na Capital, $15,5 \%$ no Interior e 15,2\% no Estado eram de pessoas com idade de 50 ou mais anos. Tal indicador revela notáveis progressos da saúde coletiva em 
nosso Estado; em 1961, tínhamos os seguintes percentuais: 45,8 ' $;$ na Capital, 37,8 no Interior e 39,6 no Estado. Muito temos que melhorar ainda, pois, num cotejo internacional, vemos que na Suécia, em 1960, $89,4 \%$ das pessoas falecidas tinham 50 e mais anos de idade.

Só se conseguem índices como êsse da Suécia quando se obtém a anulação quase total do óbito precoce de crianças e adultos jovens por intermédio da queda da mortalidade infantil e da mortalidade por doenças transmissiveis.

3.3 Curva de mortalidade proporcional: Esta curva, idealizada por Nelson de Moraes ', é formada pelos percentuais de óbitos de pessoas dos grupos etários de menos de um ano, 1-4 anos, 5-19 anos, 20-49 anos e 50 e mais anos, sôbre o total geral. Moraes estabeleceu quatro tipos esquemáticos de curva:

Tipo I, representativo de regiōes com niveis de saúde muito baixos. A curva é irregular, com elevada mortalidade nos dois primeiros grupos de idade e mais elevada ainda no grupo 20-49 anos;

Tipo II, em regiōes com baixo nível de saúde. A curva toma a forma de um " $\mathrm{J}$ " invertido;

Tipo III, encontrado em regiōes de nivel de saúde regular, com mortalidade infantil e pré-escolar ainda alta, elevando-se a curva a par. tir dos 20 anos, para atingir o máximo no grupo 50 e mais anos;

Tipo IV, característico de regiões com nível de saúde elevado. A curva toma a forma de um "J", com baixa mortalidade até os 49 anos, elevando-se em seguida, ràpidamente, a partir dos 50 anos.

Ramos ", no trabalho já citado, estudando essas curvas no Município de São Paulo, a partir de 1894, pôde demonstrar a evoluçāo dêsses indicadores e as respectivas curvas, desde a primeira, irregular, tipo I, até a última, em 1959, já com características de "J" quase perfeito.

Os dados de mortalidade proporcional referentes ao Estado de São Paulo, em 1961, são os seguintes:

$\frac{-1 \text { ano }}{29,0^{\prime} ;} \frac{1-4 \text { anos }}{9,8^{\prime} \%} \quad \frac{5-19 \text { anos }}{3,9^{\prime} ;} \quad \frac{20-49 \text { anos }}{17,7 \%} \quad \frac{50 \mathrm{c}+\text { anos }}{39,6 \%}$

Para uma imagem visual e melhor compreensão dêsses dados, apretamos a seguir um gráfico da curva correspondente e da respectiva curva da Suécia, de 1958. 
CURVA de mortalidade proporcional

estado de são paulo (1961) E suécia (1958)
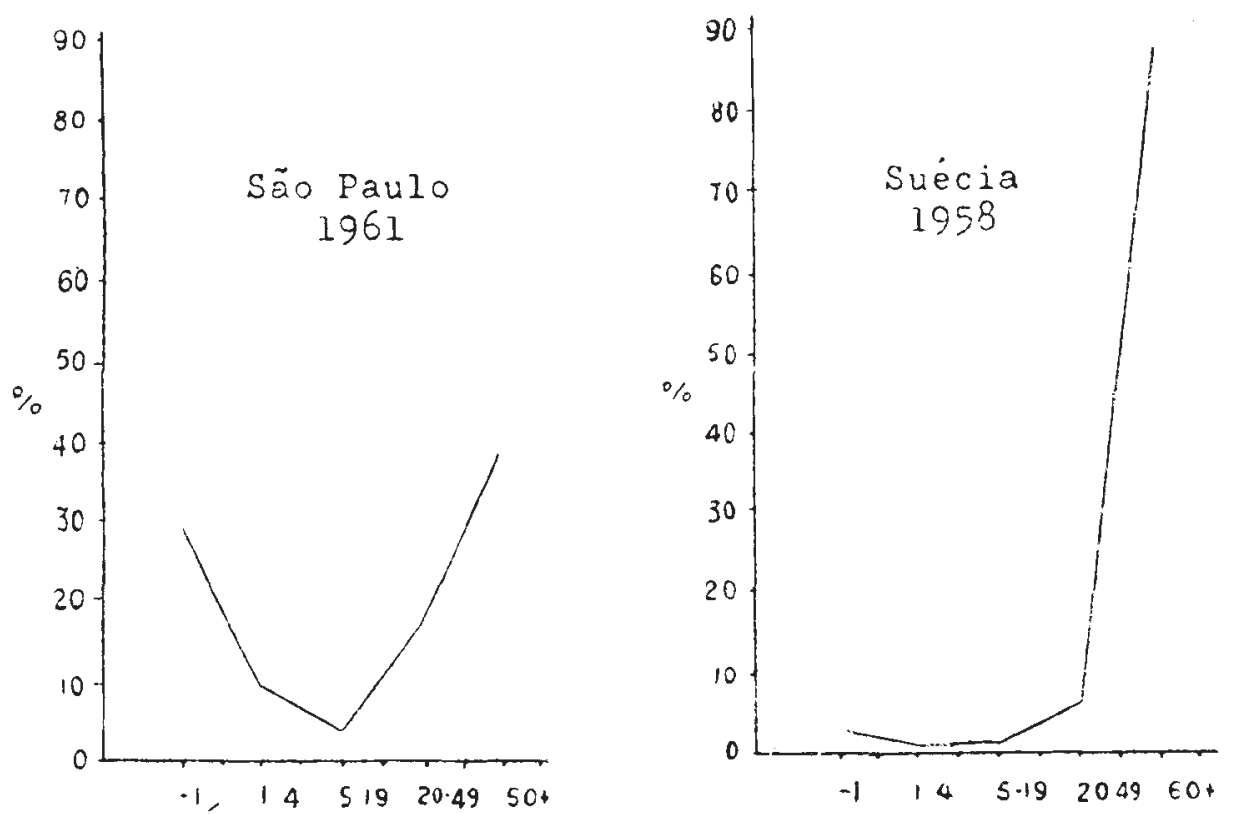

Enquanto que a curva de mortalidade proporcional da Suécia representa um "J" clássico, a do Estado de São Paulo revela um níve] de saúde regular, tipo III de Moraes. Não possuímos dados de nosso Estado para comparações com anos anteriores, mas sabemos que muito ainda teremos de fazer para diminuir a mortalidade ainda elevada dos primeiros grupos etários.

3.4 Vida média ao nascer ( $\mathrm{em}$ anos de idade): É êste um bom indicador de saúde. Os dados para São Paulo, de 1958, são os seguintes: Capital, vida média ao nascer - 62,9 anos; Interior - 58,3 anos; Estado - 59,4 anos. Para comparação, a vida média ao nascer no Município de Goiânia, em 1957, era de 37,5 anos ${ }^{7}$, correspondente à situação da Suécia em fins do século XVIII. Nos Estados Unidos, êsse mesmo indicador era de 50 anos em 1910, 59 em 1925 e 69,7 em 1960. De acôrdo com êsses dados, o Estado de São Paulo está, em relação aos Estados Unidos, com um atraso de 38 anos quanto à saúde da coletividade.

3.5 Mortalidade infantil: Êste indicador específico recebe a influência negativa de fatôres que, felizmente, são pouco encontrados em São Paulo. Trata-se de coeficiente baseado no total de óbitos de me- 
nores de 1 ano, sôbre o total de nascidos vivos, relacionado a mil dêstes últimos.

Em virtude da deficiência de dados, o coeficiente de mortalidade infantil do Estado de São Paulo só pode ser calculado a partir de 1923, quando êsse indicador era de 163,7 na Capital, 165,4 no Interior e 165,6 no Estado. O progresso nesse setor foi nítido, pois, para 1961, temos os dados seguintes: 60,2 (Capital), 83,5 (Interior) e 74,0 (Estado). Entretanto, corresponde ainda a uma elevada mortalidade de crianças menores de um ano de idade, incompativel com os conhecimentos técnicos que a Saúde Pública possui sôbre o contrôle das doenças dêsse grupo etário. Para que se tenha uma comparação internacional, veja-se que a mortalidade infantil na Suécia foi apenas de 16,6 em 1959.

3.6 Coeficiente de mortalidade por doenças transmissíceis: $\mathrm{E}$ representado pelo número de óbitos devidos a doenças transmissiveis, compreendidas no grupo I da Nomenclatura Internacional de Doenças e Causas de Morte, no qual incluimos a gripe.

Ramos "", escrevendo sôbre a importância dêsse indicador, afirma:

"Considerando que, em sua maioria as doenças transmissiveis podem ser atualmente evitadas, o respectivo coeficiente de mortalidade, se elevado, constitui indicação segura de que o nivel de saúde é baixo. A situação oposta é encontrada nas áreas de alto nível de saúde, onde a contribuição das referidas doenças para o obituário se mostra extremamente reduzida."

Vários fatôres interferem negativamente no levantamento dêsse indicador, salientando-se entre êles o elevado percentual de óbitos com causa mal ou não definida.

Os dados que levantamos mostram que êsse coeficiente foi elevado em 1900, quando o Estado estava assolado por epidemias de variola, febre amarela, febre tifóide, cólera: 415,2 na Capital, 584,3 no Interior e 566,8 no Estado todo. Para 1961, temos: 70,2 (Capital), 78,9 (Interior) e 77,1 (Estado). Fazendo uma comparação nacional e outra internacional, temos o seguinte: o coeficiente de mortalidade por doença transmissivel foi de 410,7, em 1958, em Recife - o mais elevado do País "'; no mesmo ano, na Suécia, foi de apenas 11,0. Éste último dado demonstra bem como è alta a mortalidade por essa causa no Estado de São Paulo - sete vêzes mais elevada do que a encontrada na Suécia.

A mortalidade por tuberculose foi, em 1900 , de 189,5 por 100.00 n habitantes na Capital, 74,3 no Interior e 83,8 no Estado. Em 1961, 
MASCAREnhas, R. dos S. Serviços de Saúde Pública no Estado de São Paulo... Arq. Fac. Hig. S. Paulo, 18:51-74, 1964.

foi de 24,9 (Capital), 19,5 (Interior) e 21,0 (Estado). Se reflete uma notável melhoria em relação a 1900, é porém ainda elevada - quatro vêzes mais alta do que a encontrada no mesmo ano nos Estados Unidos: 5,2 .

3.7 População servida por abastecimento público de água e sistema de esgôto: Êste indicador não pôde ser calculado para o Estado de São Paulo. Os dados que apresentamos se referem apenas ao percentual de cidades que possuem rêde pública de água e sistema de esgôto.

Dados de 1962 mostram que, dos 505 municípios do Estado, 359 dêles $(71,1 \%)$ contavam com abastecimento público de água e 234 $(46,3 \%$ ) com sistema de esgôto. É, pois, calamitosa a nossa situação em relação a êsses serviços urbanos de saneamento do meio físico. $O$ fato é ainda mais grave porque em quase tôdas as cidades o percentual de prédios servidos pela rêde de água não atinge a $80 \%$. Na própria Capital do Estado a população servida pela rêde de água representava, em novembro de $1962,85 \%$ da população do Município e apenas $48,4 \%$ era servida pela rêde de esgôto.

Antes de encerrarmos esta parte do trabalho, queremos apontar, do modo mais resumido possivel, os nossos principais problemas endêmicos rurais, justamente aquêles que mais contribuem para o ciclo pobreza-doença-pobreza; a ancilostomíase infestação é difundida por todo o Estado e sua profilaxia só se fará se calcada em medidas sociais ligadas à melhoria da habitação e da alimentação; condições geológicas e climáticas, sociais e econômicas, principalmente as referentes à desnutrição, fazem com que o problema se agrave em tôda a zona litorânea, pois a ancilostomiase infestação é normalmente acompanhada de acentuada anemia. Questão grave é a prevalência da doença de Chagas, pois, até dezembro de 1961, houve pesquisas de triatomídeos em 359 dos 505 municipios do Estado, encontrando-se em 333 dêles $(92,8 \%$ dos pesquisados) triatomídeos transmissores da doença, sendo que em $111(30,9 \%$ dos pesquisados $)$ os triatomídeos estavam naturalmente infectados. A profilaxia depende muito de medidas sociais para a melhoria da habitação rural. Outra endemia outrora inexistente, esta com incidência cada vez maior em vários focos no Estado, é a esquistossomíase. Sem ter a extensão das duas anteriores, ocasiona problema grave, pois não existe uma profilaxia específica. Todo o seu combate é calcado em medidas de melhoria do meio físico rural e suburbano: água potável, disposição adequada de excretas, etc.

Com os dados apresentados, pode-se afirmar que o Estado de São Paulo está, em relação aos seus problemas de saúde pública, nas duas fases iniciais ( $\mathrm{I}$ e II) do período que denominamos científico ${ }^{6}$. Êsses 
IIASCARENHAS, R dOS

Serviços de Saúde Pública no Estado de sāo Paulo... Arq. Fac. Hig. S. Paulo, 18:51-74, 1964.

problemas são os ligados ao saneamento do meio físico, principalmente ao abastecimento público de água, à assistência médico-hospitalar a dcentes (fase I), ao combate a doenças transmissiveis (fase II). Naturalmente terão, entre nós, prioridade sôbre os problemas relacionados à fase III (exame médico periódico de supostamente sadios) e à fase IV (higiene mental, contrôle das doenças crônicas da idade madura e da velhice).

\section{ALGUMAS CRİTICAS}

Não poderiamos enunciar algumas diretrizes para a planificação dos serviços estaduais de saúde pública de São Paulo se não tivéssemos a oportunidade de apresentar, de modo sucinto, algumas críticas. Estas são produto de nossa vivência, durante 29 anos, nos serviços estaduais de saúde pública em níveis local, regional e central e de estudo que fizemos sôbre a organização dos serviços sanitários do Estado de São Paulo, de 1889 a $1948^{5}$, bem como de nossa experiência no ensino e na pesquisa de Administração Sanitária, na Faculdade de Higiene e Saúde Pública da Universidade de São Paulo, desde 1946. Apontaremos as seguintes críticas, que consideramos básicas:

4.1 Deficiência de pesquisas: São poucos, muito poucos mesmo, os trabalhos sôbre a organização "de fato" - e não a legal, de nossos serviços estaduais de saúde pública. $O$ mesmo se diga em relação à prevalência de doenças transmissiveis, principalmente as crônicas, pois as verbas orçamentárias existentes são aplicadas às atividades técnicoadministrativas de rotina e à criação ou ampliação de órgãos, destinados, muitas vêzes, à satisfação de uma clientela política.

Os órgãos de pesquisa integram outros órgãos de assistência hospitalar e de atividades de contrôle local de doenças, como no caso da tuberculose, da lepra, das doenças mentais, da proteção à criança e à mãe, etc. Em quase todos os países tecnològicamente mais avançados do que o nosso, os órgãos de pesquisa são institutos autônomos, estruturados para essa finalidade, possuindo só as poucas atividades de campo necessárias às investigações.

4.2 Deficiência de dados: O Estado não dispōe de informações estatisticas fidedignas, pois não existe um sistema adequado de coleta de dados relativos à mortalidade e à prevalência de doenças de interêsse social, à produção de serviços e à avaliação das atividades dos órgãos estaduais de saúde.

Como já foi dito, o percentual de óbitos com causa não-declarada ou mal-definida é elevado em todo o interior do Estado há decênios, 
sem que se tenham tomado medidas para, se não resolver, pelo menos mitigar a situação.

A Secretaria da Saúde Pública e da Assistência Social não publica sequer um relatório anual de suas atividades, o mesmo ocorrendo com a grande maioria dos órgãos que a integram.

4.3 Falta de estruturação da Secretaria da Saúde Pública e da Assistência Scialal: Esta Secretaria de Estado foi criada com a divisão da antiga Secretaria da Educação e Saúde Pública, em junho de 1947. O decreto-lei baixado para essa medida estabeleceu o conhecido prazo de 90 dias para a elaboração de um projeto de lei que estruturasse êsse amontoado de órgãos que formava, outrora, a parte sanitária da Secretaria da Educação e Saúde Pública. Desde então, vários anteprojetos de estrutura foram apresentados, seja ao Secretário de Estado, seja mesmo ao Governador, mas nenhum chegou a transformar-se em projeto de lei, em virtude não apenas da inércia administrativa, mas também da pressão de grupos interessados - políticos ou administrativos.

Tendo-se originado na escola francesa de higiene - herdeira que é do antigo Serviço Sanitário do Estado, a atual Secretaria de Saúde Pública e da Assistência Social continuou com a diretriz de criação de órgãos especializados, para atender ao contrôle desta ou daquela doença (dispensários de tuberculose e de lepra, postos de malária e tracoma) ou para assistir um determinado grupo etário (dispensários e postos de puericultura), encarecendo demasiadamente os cofres públicos e dificultando, mesmo em nivel local, a coordenação de atividades.

Em nível regional nada foi feito para a descentralização de atividades, apesar de o Estado de São Paulo ter uma população de $13 \mathrm{mi}$ lhões de habitantes, superior à maioria dos países latino-americanos. As delegacias de saúde, em número de 19, jamais foram estruturadas e as funções de delegado de saúde continuam, em virtude de circuntâncias que fogem à ação de seus titulares, como meros degraus burocráticos entre a unidade local - PAMS, ctentro de saúde, unidade integrada - e o órgão central - Divisão do Serviço do Interior. No Departamento Estadual da Criança vamos encontrar um milhar de unidades locais — postos de puericultura — subordinadas a um só diretor do órgão central localizado na Capital e que trabalha em regime de tempo parcial.

Subordinados "de fato" ao Secretário de Estado estão 24 órgãos tècnicamente autônomos. A grande maioria dêstes não está devidamente estruturada, pois a sua organização atual é a mesma daquela baixada por decretos-leis de 1938-39, quando foi criado o Departamento de Saúde do Estado, em substituição ao Serviço Sanitário. 
4.4 Inexistência de planos gerais de saúde püblica: Ano vem, ano passa, sem que surja um plano geral, plurienal, para as atividades estaduais de saúde, seguido dos necessários prcgramas anuais de atividades. Dêsse modo, o Secretário de Estado observa a Secretaria da Saúde Pública de modo fragmentário, de acôrdo com as informações prestadas pelos 24 diretores de órgãos que lhe estão subordinados.

Não existindo planos gerais, não existe, conseqüentemente, um sistema de prioridades e cada Secretário de Estado tem tendència a dar ênfase a êste ou aquêle setor da saúde pública, conforme suas conveniências políticas ou o seu interêsse profissional, ou, ainda, a pressāo de um amigo, diretor de um órgão a êle subordinado.

Não existindo planos gerais, não existe, conseqüentemente, um sistema de avaliação - quantitativa e qualitativa - das atividades de saúde pública. As verbas são despendidas sem qualquer contrôle técnico-administrativo, a não ser aquêle contábil exercido pela Secretaria da Fazenda e pelo Tribunal de Contas do Estado.

4.5 Inexistência quase total de coordenação de atiridades: Os serviços estaduais de saúde pública de São Paulo muito pouco se articulam com os serviços federais de saúde, com serviços similares das autarquias da União, principalmente os dos órgãos de previdência, e com os serviços municipais de saúde.

Essa falta de coordenação, além de dificultar a implantaçāo de um plano geral de saúde para o Estado de São Paulo, encarece os serviços estaduais de saúde, pois êstes exercem atividades que deveriam pelo menos ser financiadas por outros órgãos. Os hospitais-gerais do Estado e os especializados - tuberculose, lepra, psicopatas - recebem grande número de pessoas de outros Estados da Federação, vindas especialmente para internar-se. Seria justo que as despesas com a internação dêsses doentes ficassem a cargo da União. O mesmo se diga dos milhares de segurados dos IAPS que são internados nos hospitais estaduais de tuberculose, de saúde mental, sem que êsses institutos financiem o tratamento médico-hospitalar dêsses segurados.

4.6 Legislação inadequada: Sôbre o assunto, assim nos referimos em outro trabalho:

"É assombroso o desenvolvimento da Saúde Pública nestas últimas décadas, em grande parte pela evolução surpreendente da Medicina. A legislação não tem acompanhado essa evolução, principalmente por ficar entregue a legisladores leigos na matéria e, além do mais, sujeitos a pressão de grupos.

"O Regulamento da Alimentação Pública do Estado de São Paulo foi baixado pelo decreto-lei n." 15.642, de 9-2-46. 
É uma lei muito extensa, que entra em minúcias técnicas em seus 1072 artigos. Foi prevista a atualização dessa lei a cada 5 anos. Dois anteprojetos foram preparados pelas autoridades sanitárias do Estado, mas nenhum dêles teve andamento na Assembléia Legislativa.

"Vários serviços estaduais de saúde baseiam sua ação em códigos sanitários antigos, completamente em desacôrdo com a problemática e técnica atuais; tal fato ocorre no Estado de São Paulo, cujo código, ainda vigente em algumas de suas disposições, data de 1918." "

Uma reação surgiu, entre nós, contra êsse estado de coisas e um nôvo projeto de Código Sanitário, sucinto, com apenas uma dezena de artigos, revogando tôda a legislação anterior, foi encaminhado à Assembléia Legislativa pelo Governador, por solicitação da Secretaria de Estado. Uma vez aprovado êsse projeto de lei, a regulamentação, através de decretos do Poder Executivo, apresentará, em detalhes, a parte técnica do contrôle estatal no saneamento do meio, na alimentação pública, no contrôle de doenças infecciosas, bem como na proteção à mãe, à criança, ao adulto, ao trabalhador, etc.

4.7 Inexistência de carreiras: Os serviços de saúde pública até hoje não conseguiram implantar as carreiras sanitárias, e entregam a direção de seus órgãos centrais, regionais e locais a profissionais, geralmente médicos, que trabalham em regime de tempo parcial e sem o conhecimento do que seja o "público" e das técnicas - médicas, de enfermagem, de administração hospitalar, de engenharia sanitária, de veterinária, de odontologia, de educação - empregadas de acôrdo com normas científicas em favor da saúde da comunidade.

Por outro lado, não acompanha a Secretaria de Estado a tendência de todo país subdesenvolvido de dar ênfase à formação, em escala cada vez mais crescente, de pessoal auxiliar, principalmente para o saneamento do meio físico e enfermagem. A admissão dêsses profissionais continua a ser feita exclusivamente pelo critério político, sem que seja condicionada à apresentação sequer de um certificado de conclusão de curso primário.

4.8 Atitude paternalista: Devido a uma tradição vinda da Península Ibérica, o brasileiro, como todo latino-americano, acostumou-se a receber do Estado, passivamente, tudo o que êste lhe oferece, muitas vêzes sem que êle peça. Temos uma tradição paternalista em nosso serviço público e, dêsse modo, a população não participa ativamente das atividades de saúde pública, contrariando o próprio conceito dessa ciência apresentado, já em 1920, por Winslow ${ }^{12}$. 
MASCAREnhas, R. dos S. Serviços de Saúde Pública no Estado de São Paulo... Arq. Fac. Hig. S. Paulo, 18:51-74, 1964.

4.9 Intervenção da politica: A Secretaria da Saúde Pública e da Assistência Social é, talvez, a Secretaria de Estado que mais recebe o impacto da influência política.

órgãos locais, por exemplo de tuberculose, podem ser criados onde não há tuberculosos em número suficiente para justificar essa medida. Uma delegacia de saúde - órgão regional que normalmente abrange umas três dezenas de municípios - foi criada para um só municipio, tendo a Assembléia rejeitado o veto do Poder Executivo a essa medida que atenta contra qualquer princípio técnico de Administração Sanitária.

Um oftalmologista pode ser nomeado para dirigir um órgão de combate à malária, um pediatra para um serviço de tuberculose, pois, para o serviço público, dois títulos são necessários: diploma de médico e indicação de líder político. Fiscais sanitários são nomeados ou admitidos por simples indicação de partido político, mesmo que tenham freqüentado apenas o primeiro ou o segundo ano da escola primária. Servidores são removidos, ou não podem ser removidos, por pressão de grupos políticos. Uma vez nomeado ou admitido, o servidor relapso não pode ser afastado, pois possui mais direitos do que deveres e busca a proteção de políticos ou da classe.

A situação tornou-se ainda mais grave, pois em virtude da acentuada inflação e do sistema dominante de aumento de vencimentos, em que houve periodos de aumentos proporcionalmente maiores aos servidores de padrões de vencimentos mais baixos, torna-se difícil encontrar um técnico de nível universitário - médico, engenheiro, dentista - que deseje ingressar no serviço público do Estado, e empregar, de modo eficiente, as horas de trabalho que legalmente deve prestar. A função pública estadual tornou-se principalmente para o profissional com diploma de curso superior um "bico" a auxiliá-lo na luta cotidiana para o seu sustento e o dos seus familiares.

Jamais vimos, em nossos trinta e dois anos de serviço público, o afastamento, nem mesmo a diminuição significativa, dessa pressāo política sôbre os serviços estaduais de saúde.

\section{DIRETRIZES PARA OS SERVIÇOS DE SAÚDE DO ESTADO}

Exporemos nesta última parte do trabalho algumas diretrizes para os serviços de saúde do Estado de São Paulo, diretrizes que representam nossa opinião pessoal. Uma reorganização dêsses serviços está na dependência de um estudo mais aprofundado, feito por uma equipe de técnicos, representativa não apenas dos profissionais que mais trabalham nas atividades de saúde, como também de expoentes de órgãos públicos ou privados que se interessam por êsse ramo de atividade. 
MASCAREnhas, R. dos S. Serviços de Saúde Pública no Estado de São Paulo... Arq. Fac. Hig. S. Paulo, 18:51-74, 1964.

Apontaremos aqui as diretrizes, seguindo um roteiro que significa também a prioridade que dariamos às mesmas:

5.1 Incentivo d̀ pesquisa: Nenhum povo pode sobreviver na evolução tecnológica dêste século sem que tenha os seus órgãos de pesquisas, principalmente aquelas que irão determinar o incremento de atividades necessárias ao seu desenvolvimento sócio-econômico. Podemos importar de centros tecnològicamente mais adiantados idéias, técnicas, mas a solução para os nossos problemas tem que ser nossa, calcada em nossa realidade sócio-econômica.

No que tange aos problemas de saúde, podem ser êles estudados por órgãos da própria Secretaria da Saúde Pública e da Assistência Social, por estabelecimentos de ensino universitário ou, mesmo, por institutos particulares. Duas medidas precisariam ser tomadas:

(1) Financiamento adequado para as pesquisas realizadas pela própria Secretaria de Estado ou executadas, mediante convênio, por outros órgãos. Dinheiro existe bastante. $\mathrm{O}$ que é preciso é que se tenha coragem de gastá-lo menos em órgãos "linha" (centros de saúde, dispensários de tuberculose, etc.), com rotinas, e mais em investigações. O govêrno do Estado gastou, em 1960, nos serviços rotulados oficialmente como de saúde pública, a importância de Cr\$ 10,981 bilhões, o que corresponde a $7,9 \%$ do orçamento e a 818,7 cruzeiros "per capita" (3,09 dólares americanos, na época). Se existisse a possibilidade de medirmos os resultados dos serviços estaduais de saúde, verificaríamos que êstes não seriam prejudicados se retirássemos $10 \%$ das verbas e os destinássemos ao financiamento de pesquisas.

(2) Organização de institutos, técnica e administrativamente autônomos, para as pesquisas da Secretaria de Estado. Seriam assim criados os institutos de higiene, para a higiene materna, infantil, mental, etc.; institutos de doenças transmissiveis (infecciosas agudas, endemias rurais, tuberculose, lepra, etc.); instituto de nutrição; instituto de doenças crônicas não-transmissíveis (cardiovasculares, câncer, diabetes, etc.) e outros. Cada instituto teria, para suas atividades de campo, um pequeno hospital e uma unidade local, por êle dirigidos ou colocados à sua disposição.

5.2 Melhoria da coleta de dados estatísticos: A coleta de dados estatísticos é uma função vital para os órgãos de saúde pública, para mensurar os fatos sociais, econômicos, biológicos de interêsse para a saúde, bem como as atividades dêsses mesmos órgãos e os resultados 
MAsCARENHAS, R. dos $\mathrm{S}$. Serviços de Saúde Pública no Estado de São Paulo... Arq. Fac. Hig. S. Paulo, 18:51-74, 1964.

de sua ação. Só assim teríamos possibilidade de planejar adequadamente a ação sanitária. Torna-se mister a criação, dentro da própria Secretaria, de um órgão para as suas atividades de bioestatística, órgão êsse que se articularia, no aspecto técnico, com o Departamento de Estatística do Estado.

5.3 Afastamento da ação negativa da política: Somos dos que acreditam que jamais, seja qual fôr o regime politico, será afastada a ação da política nos órgãos públicos, pois sempre existiu, existe e existirá uma função social do político, seja êste profissional ou não. É necessário, porém, que essa ação política não se faça para satisfazer a clientela de empreguismo - com candidatos técnica e moralmente incapazes - ou para satisfazer as aspirações de seus núcleos de eleitores - com a criação de novos órgãos de âmbito local ou regional. Cabe ao político influir na formulação das diretrizes de saúde, no planejamento destas e, mesmo, indicar candidatos a funções públicas, desde que êstes se apresentem devidamente preparados para as mesmas.

5.4 Legislação sanitária adequada: A legislação sanitária precisa ser tôda atualizada, iniciando-se essa atualização por uma delimitação entre as atividades de saúde pública do govêrno da União e as dos governos estaduais, evitando-se a tendência atual dos órgãos federais de detalhar ao mínimo, num sistema rígido, as normas técnicas do Código Sanitário da União.

A parte de lei pròpriamente, da legislação sanitária, deve ser a mais reduzida e a mais geral possivel, deixando-se ao Poder Executivo o direito de baixar periòdicamente, de acôrdo com a evolução científica, as normas técnicas.

5.5 Reorganização dos serviços estaduais de saúde pública: Não seria pròpriamente uma reorganização e sim uma organização, pois essa Secretaria de Estado jamais foi organizada. Não se pode discutir em poucas linhas essa organização. Apresentaremos apenas algumas diretrizes, baseadas na Ciência da Administração:

(1) Conselho Superior de Saúde: Ao lado do Secretário de Estado, deve existir um órgão com funções exclusivamente consultivas para assessorá-lo na formulação das diretrizes gerais de sua ação e na coordenação das atividades dos departamentos centrais. É preciso que seja integrado por técnicos de reconhecido valor, com pelo menos 10 anos de atividades em saúde pública, escolhidos dentro e fora da Secretaria de Estado, nomeados por periodo fixo, pelo sistema de rodizio. 
MASCARENHAS, R. dos S. Serviços de Saúde Pública no Estado de São Paulo... Arq. Fac. Hig. S. Paulo, 18:51-74, 1964.

(2) Separação das atividades "linha" das de investigação, criando-se, como já foi dito, institutos de pesquisa. As atividades "linha" seriam dirigidas através de poucos órgãos diretamente subordinados ao Secretário de Estado. Poderia haver, por exemplo, uma subsecretaria ou órgão equivalente para as atividades diretamente dirigidas ao público (unidades sanitárias locais, serviços centrais de saneamento, órgãos técnicos gerais, etc.), outra para as atividades hospitalares, outra para os institutos de pesquisa, e um departamento para as atividades centrais de administração.

(3) Descentralização de ađividades técnicas e administrativas em 9 ou 10 divisões regionais, que seriam, em sua área de ação, como um departamento de saúde. Cada divisão regional teria um número adequado de técnicos para supervisão das atividades das unidades sanitárias, todos êles com curso de Saúde Pública e trabalho em regime de tempo integral.

(4) Unidades locais polivalentes. Tôda a ação local deve ser entregue a um órgão local, tenha o nome que tiver (pôsto, centro de saúde, unidade integrada), que executa, sob chefia única de médico-sanitarista, tôdas as atividades de saúde de âmbito local e de responsabilidade da Secretaria de Estado. Essa unidade, com suas subunidades, estaria integrando um distrito sanitário, em cuja sede estaria a unidade sanitária local mais complexa, com serviços especializados de tuberculose, de lepra, de higiene materno-infantil, de enfermagem, de nutrição, etc.

(5) Formação de pessoal: A Secretaria da Saúde Pública precisa reconhecer, não apenas em palavras, mas em atos, que a direção dos órgãos centrais estruturados segundo a finalidade, a dos órgãos regionais e suas respectivas assessorias, e, ainda, a dos órgãos distritais, deve ser entregue a técnicos que se especializaram em Saúde Pública. Há, pois, necessidade de muito mais médicos, enfermeiros e, também, para os órgãos regionais, de engenheiros, veterinários, dentistas, educadores, etc., com curso de Saúde Pública.

Torna-se urgente, também, a formação de pessoal auxiliar, principalmente técnicos de laboratório, de raios $\mathrm{X}$, inspetores $\mathrm{e}$ fiscais sanitários, auxiliares de enfermagem e visitadoras. Sem estas últimas não haverá dinamismo nas atividades dos órgãos locais de saúde pública.

Não poderá ser descuidada a formação de outros profissionais, como médicos consultantes especializados, profissionais (médicos, farmacêuticos, químicos, veterinários) para os laboratórios 
centrais e regionais, outros profissionais para os hospitais do Estado, etc.

(6) Criação de carreiras: Por melhor que seja a organização estudada, perderá completamente o seu valor se não fôr implantada por pessoal devidamente preparado. $O$ pessoal devidamente preparado, por sua vez, não existirá se não fôr atraido para o serviço público pelas carreiras profissionais. Uma das primeiras questões na criação de carreiras é a estipulação los vencimentos de cada profissional. Os vencimentos dos cargos iniciais de carreira devem ser estabelecidos mediante critérios já bem conhecidos, onde entram, por exemplo, como elementos de ponderação, a formação profissional, a posição social do ocupante, as atividades que exerce, o número de horas diárias de trabalho, etc.

As carreiras devem também estabelecer o trabalho em regime de dedicação exclusiva ao serviço público para os diretores de órgãos centrais e regionais, para os assessores dêstes, para os médicos dirigentes dos órgãos distritais, bem como, quando necessário, para o pessoal profissional em função nos laboratórios centrais e regionais e na administração dos hospitais.

A organização da Secretaria de Estado deve permitir a criação da carreira de médico-sanitarista, de tal modo que êste, quando nela ingressar, saiba que irá para uma atividade local no interior do Estado e que terá promoçōes, para atingir funçōes mais altas, em unidades sanitárias mais complexas, até chegar à Capital.

(7) Planejamento: A ação sanitária deve ser tôda formulada através de planos plurienais, com as respectivas programações anuais. Os planos da Secretaria de Estado devem estar entrosados com o plano geral do Govêrno. Devem abranger o trabalho de todos os órgãos, no Estado, interessados em questōes de saúde, sejam êstes federais, municipais, autárquicos ou privados. O plano deve prever, por exemplo, articulação a mais intensa possivel com os hospitais beneficentes privados, de tal modo que êstes se transformem, de suplicantes de pagamento de um leito-dia, cujo custo é usualmente calculado por baixo, em peças integrantes do plano de saúde, tendo os seus direitos e seus deveres estabelecidos em convênios. Exemplo de como o Estado pode atuar bem nesse setor é a entrega do hospital regional de tuberculose de Catanduva, próprio da Secretaria de Estado, feita a uma irmandade religiosa que o dirige integralmente, dentro das normas técnicas estipuladas pelos órgãos competentes da Secretaria. Como resultado, vemos o leito-dia baixar a cêrca de $50 \%$ do custo do leito de hospital de tuberculosos dirigido pelo Estado. 
(8) Criação de um sistema de prioridades: Pela sua importância, demos destaque a esta parte.

Um sistema de prioridades deve ser criado de acôrdo com as finalidades, organização, pessoal disponivel e, principalmente, verbas, da Secretaria de Estado ou de órgãos que financiam as atividades dos serviços privados.

Sabemos que em nenhum país do mundo é possível, financeira e tècnicamente, ao govêrno, atacar com a mesma intensidade tôdas as atividades necessárias à saúde da população. Tem que fazer, mediante critérios técnicos, a seleção das mesmas. Não desejamos nos alongarmos, entretanto, no mérito da questão, mas afirmaremos apenas que deve ser dada pelo Estado prioridade número um, no que tange à saúde da população, aos serviços locais de abastecimento público de água - financiando a construção ou reconstrução de rêde de água e supervisionando "de fato" as atividades dos serviços municipais de abastecimento, para que não fiquem submetidos, como sói acontecer, a desvirtuamento técnico, principalmente quanto ao tratamento da água. Prioridade número um deve também ser dada pela Secretaria de Estado ao incentivo da assistência médico-hospitalar por hospitais-gerais particulares, bem como ao combate a doenças transmissiveis. Destas, são passiveis de erradicação a malária, a variola, a poliomielite, a febre amarela urbana, a difteria e de contrôle, a febre amarela silvestre, a febre tifóide, o tétano. De erradicação, ou mesmo contrôle, mais difícil são as endemias rurais, cuja profilaxia exige medidas de caráter social, conforme estudou Coutinho ${ }^{1}$. Dentre estas, apontaríamos a esquistossomíase, a doença de Chagas, a ancilostomíase. Não incluímos aqui a malária porque esta já está pràticamente erradicada, pois, de dezenas de milhares de casos que tínhamos outrora, surgem algumas centenas nestes dois últimos anos, considerando-se aqui apenas os casos autóctones.

Ao finalizarmos êste trabalho, desejamos afirmar que cada vez mais se faz sentir, em nosso país, a necessidade de uma mudança radical da atitude do Govêrno para com a população; deve abandonar o paternalismo até agora adotado e procurar obter a participação do povo na formulação das diretrizes e na execução das atividades desenvolvidas pelos serviços públicos.

Sòmente assim poderemos atingir a meta ideal dos serviços de saúde de qualquer coletividade.

NÃO FAZER SAÚdE PÜBLICA PARA O POVO, E SIM COM O POVO. 
MASCARENHAS, R. dos $\mathrm{S}$. Serviços de Saúde Pública no Estado de São Paulo... Arq. Fac. Hig. S. Paulo, 18:51-74, 1964.

ANEXO - América Latina. Renda per capita e esperança de vida ao nascer.

Esperança de vida ao nascer, 1955-1960.

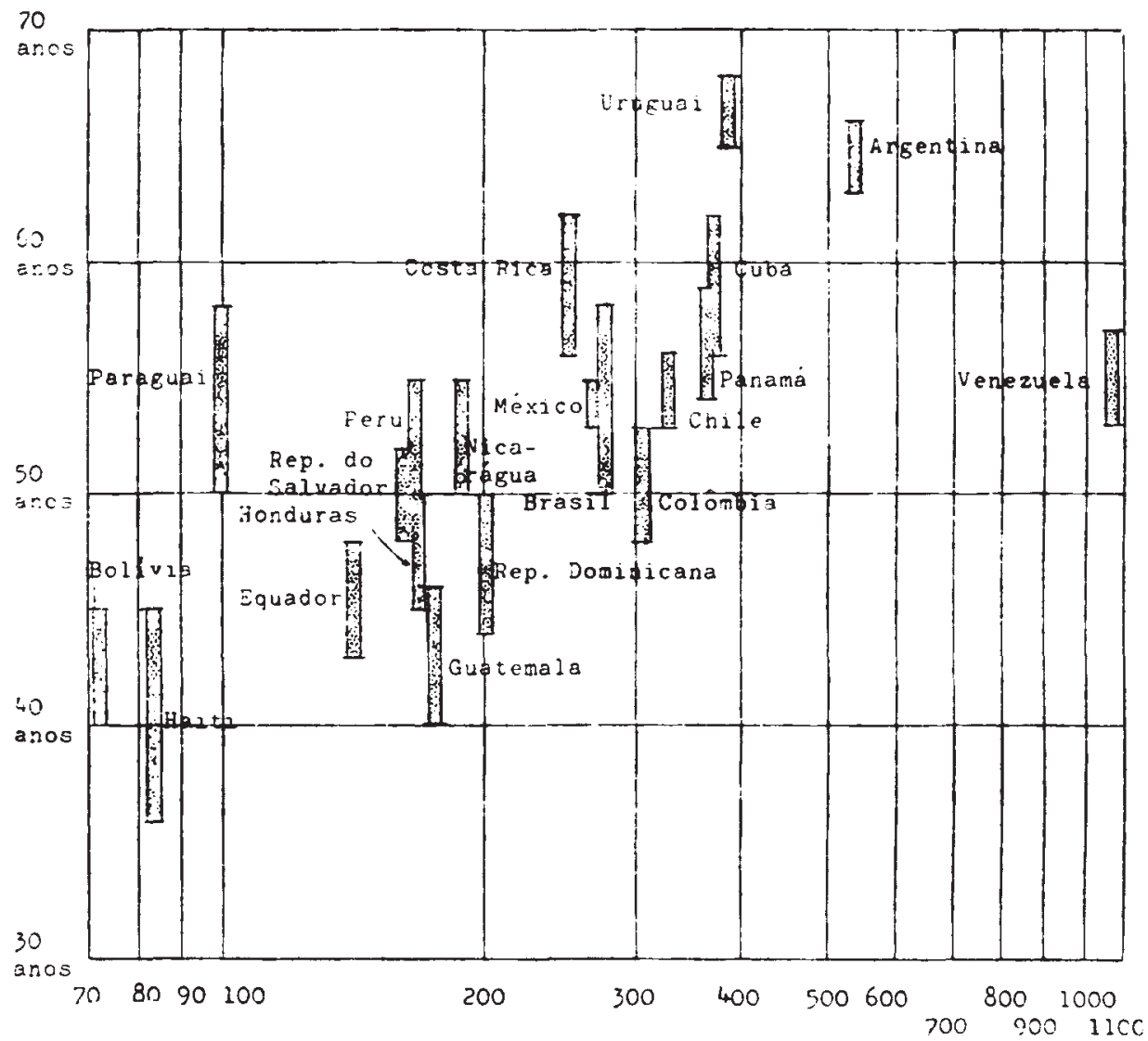

Renda nacional per capita (em dólares), 1959

Fonte: SALVY, Alfred. La population des pays d'Amérique Iatine. Vue génèrale sur leus état et leur croissance. Population, 18(1):49-64, jan.-mars 1963. 


\section{RESU M O}

O autor apresenta, no trabalho, comentários e sugestões a respeito dos Serviços de Saúde Pública no Estado de São Paulo, Brasil.

Inicia expondo conceitos de Saúde Pública e, em seguida, tece consideraçōes sôbre padrão de vida e Saúde Pública, citando dados da América Latina.

Estende-se, com mais detalhes, no que se refere aos niveis de saúde do Estado de São Paulo, apresentando dados, em geral dos anos de 1900 ? 1960 ou 1961, tais como: coeficiente de mortalidade geral, razão de mortalidade proporcional, vida média ao nascer, mortalidade infantil, coeficiente de mortalidade por dcenças transmissíveis, comparando-os com os de outros países.

Tece, finalmente, algumas críticas aos Serviços de Saúde Pública do Govêrno do Estado de São Paulo, apontando diretrizes (policies) para a solução de seus problemas mais imediatos.

\section{S U M M A R Y}

This paper analyses the administration of public health agencies in the State of São Paulo, Brazil.

The author presents health and public health concepts and briefly comments on the relationships between standard of living and public health on the basis of Latin America date.

Date related to all causes of death, life expectancy, infant mortality to mention only a few, from the years 1900 and $1960-1961$ is also presented. Comparison between the State of São Paulo and other countries is made.

The author ends up by indicating a few aspects of São Paulo public health agencies that need to be improved, suggesting policies whose implementation will help to solve some of the problems.

\section{REFERENCIAS BIBLIOGRÁFICAS}

1. COUTINHO, J. O., AlENCAR, J. E. \& FREITAS, C. A. Problemas médicosanitários de áreas subdesenvolvidas. Rev. bras. Malariologia e Doenças (rop.. 15(1):157-189, jan./mar. 1963 .

2. DESFNVOLVIMENTO \& CONJUNTURA. Rio de Janeiro. Principais características do subdesenvolvimento. 6(5):17-25, maio 1962.

3. HORWITZ, A. O papel da Organização Pan-Americana da Saúde no programa de desenvolvimento econômicr da OEA. Washington, Organização PanAmerirana da Saúde. 1961. 16 p. (Publs. Várias, 57). 
4. LEAVELL, H. R. \& CLARK, E. G. Preventive Medicine for the doctor in his community. 2nd ed. New York, McGraw-Hill, 1958. 689 p.

5. MASCARENHAS, R. S. Contribuição para o estudo da administração sanitária estadual em São Paulo. São Paulo, 1949.565 p. (Tese de docência-livre. Faculdade de Higiene e Saúde Pública da Universidade de São Paulo).

6. - Administração em Saúde Pública no Brasil. 99 p. (Apresentado ao I Seminário de Saúde Pública da Associação Médica Brasileira - III Congresso da A.M.B. - Fortaleza, 1963. Datilografado).

7. MORAES, N. L. A. Níveis de saúde de coletividades brasileiras. Rev. Serr: Esp. Saúde (SESP), 10(2):403-497, dez. 1959.

8. ORGANIZATION MONDIALE DE LA SANTE. La mesure des niveaux de la santé. Rapport d'un groupe d'étude. Gèneve, 1957. 34 p. (Sér. Rapp. Techn., 13\%).

9. PAUla SOUZA, G. H. A Organização Mundial de Saúde. [Rio de Janeiro] Serviço de publicações do Ministério das Relaçōes Exteriores [1948] 56 p. (Documentos, 5).

10. RAMOS, R. Indicadores do nivel de saúde: sua aplicação no Município de São Paulo. (1894-1959). São Paulo, 1962. 136 p. (Tese de doutoramento. Faculdade de Higiene e Saúde Pública da Universidade de São Paulo. Mimeografado).

11. SAUVY, A. La population des pays d'Amérique Latine. Vue générale sur leur état et leur croissance. Population, 18(1):49-64, jan./mars 1963.

12. WINSLOW, C. E. A. The untilled fields of public health. Science, 51(1306): 23-33, jan. 1920 .

13. - The cost of sickness and the price of health. Geneva, World Health Organization, 1951. 106 p. (Monograph series, 7).

\section{FONTES DOS DADOS ESTATÍSTICOS}

14. ANUÁRIO [DO DEPARTAMENTO DE ESTATÍSTICA DO ESTADO DE SÃO PAULO] 1961. São Paulo, 1963.

15. ANUÁRIO ESTATÍSTICO DO BRASIL, 1962. Rio de Janeiro, IBGE. Conselho Nacional de Estatística [1962].

16. 1963. Rio de Janeiro, IBGE. Conselhc Nacional de Estatística [1963].

17. DEMOGRAPHIC YEARBOOK, 1961. New York, United Nations, 1961. 